\title{
Sistema de Regulagem Automática PaRa EsPelhos Retrovisores de Veículos ARTiCULAdos
}

\author{
Igor Augusto Alves Batista ${ }^{1}$ Gabriel Hamdan Ferreira ${ }^{2}$
}

E-mails: igoraugusto501@hotmail.com, ghamdan.eng@gmail.com

\section{RESUMO}

Hoje há uma crescente preocupação com a segurança no transporte rodoviário. A indústria deste segmento apresenta constantemente veículos cada vez mais seguros e confortáveis. Mesmo com toda tecnologia embarcada, manobrar veículos articulados exige grande perícia de seu condutor principalmente em manobras à ré. Estes veículos em geral, oferecem pouca visibilidade traseira, pois só é possível visualizar a parte posterior através dos espelhos retrovisores laterais. Este sistema tem como principal objetivo aumentar a segurança dos condutores de veículos articulados, seja de passageiros ou de carga. Este sistema amplia o campo de visão, regulando o espelho automaticamente às situações nas quais o motorista de um veículo articulado perca a visibilidade da parte posterior da composição veicular tal como realizando uma curva ou em situações de manobra. Desta forma, este sistema visa reduzir o risco de acidentes, aumentando o conforto e aumentando a produtividade. Este funcional sistema tem uma estrutura simples de funcionamento que consiste de três básicos componentes de fácil aquisição para a indústria: Espelho lateral com regulagem elétrica (normal de produção), uma central eletrônica e sensores na articulação do veículo.

\section{INTRODUÇÃO}

Há uma crescente preocupação com a segurança no transporte tanto de veículos comerciais de carga quanto de passageiros. No ramo de veículos de passageiros a crescente demanda por mobilidade urbana fez crescer a venda de ônibus articulados que tem por objetivo o transporte rápido e de grande demanda de passageiros, assim como o metrô. No ramo de caminhões há também uma crescente demanda por veículos cada vez maiores e mais pesados (bi-trens, bitremzão e rodo-trens), a fim de transportar uma maior quantidade de carga possível em uma única composição veicular.

Um caminhão tipo cavalo-mecânico novo, possui, em sua grande maioria, a tecnologia (e o preço) que se equipara a de um veículo de passeio importado. Mesmo com toda tecnologia embarcada, manobrar veículos articulados principalmente à ré é uma manobra árdua até para os motoristas mais experientes. Estes veículos em geral oferecem pouca visibilidade traseira, pois só é possível visualizar a parte posterior através dos espelhos retrovisores laterais. Quando o veículo está realizando uma curva, seja em manobras de pátio ou em movimento, o semi-reboque está desalinhado em relação ao veículo trator e o motorista perde a visibilidade do final da composição veicular no espelho retrovisor. Logo, para realizar uma manobra de estacionamento, normalmente o motorista necessita de um ajudante para evitar acidentes. 


\section{OBJETIVO}

O Sistema de Regulagem Automática para Espelhos Retrovisores de Veículos Articulados tem como principal objetivo aumentar a segurança das composições veiculares seja de passageiros ou de carga. Este sistema amplia o campo de visão nos espelhos laterais automaticamente em situações nas quais o motorista perca a visibilidade da parte traseira da composição. Desta forma, possibilita que o motorista mantenha em todas as condições sua visibilidade total, seja realizando uma curva ou em situações de manobra, reduzindo assim, o risco de acidentes, aumentando o conforto e reduzindo tempo de manobra, aumentando a produtividade.

\section{SITUAÇÃO ATUAL}

1.1. Estudo de caso em uma empresa de transporte rodoviário de cargas.

Em um estudo de caso realizado na Empresa TransCouto Ltda., situada em Betim/MG pode-se constatar que em pequenas manobras o motorista passa a não visualizar a parte traseira da composição veicular, pois parte do semi-reboque entra completamente no campo de visão dos espelhos retrovisores laterais. Para este estudo utilizou-se de uma composição veicular com um Iveco Stralis 380 e uma semireboque Randon Carga Seca de 15m. A Figura 1 abaixo demonstra a visão do motorista no espelho retrovisor do lado direito na posição em que o veículo encontrase ao lado. Note-se, que em um ângulo da curva pequeno, de aproximadamente 20 graus, não há mais visibilidade do final do semi-reboque.
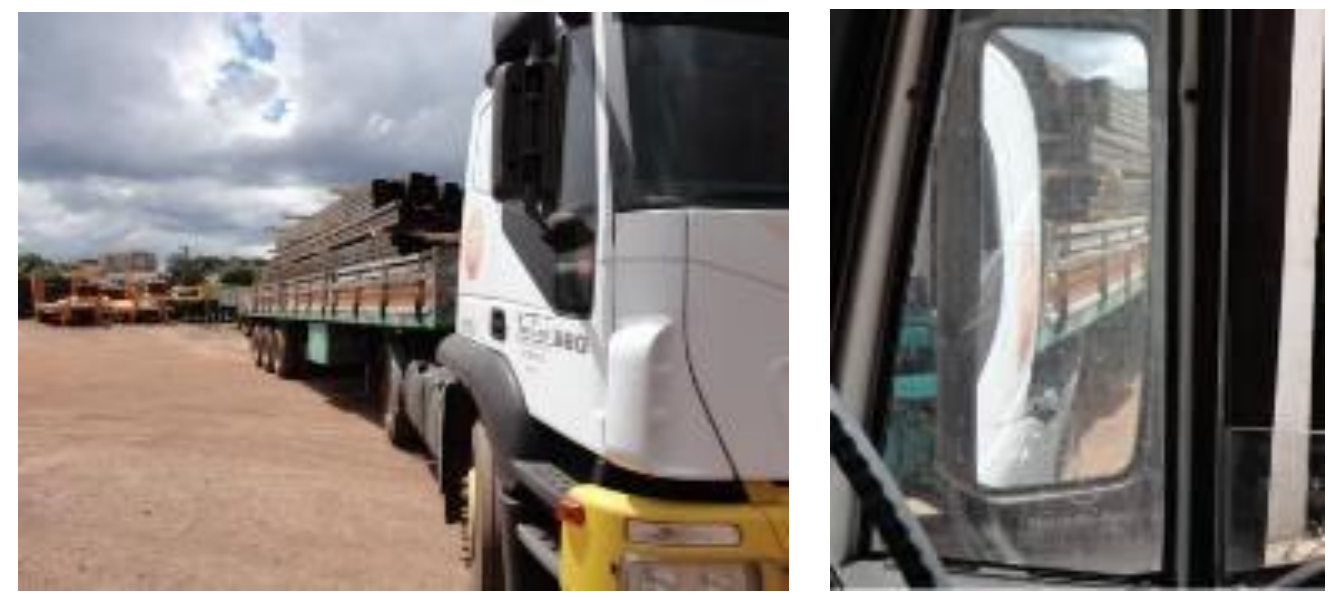

Figura 1: Veículo articulado em curva e a visão do motorista no espelho retrovisor direito (Fonte: Autor)

Segundo o gerente da empresa, Sr. Ricardo Camargos, pequenos acidentes e esbarrões são comuns dentro do pátio da empresa, principalmente por motoristas novatos. A falta de visibilidade no espelho retrovisor é a principal causa destes incidentes, segundo Camargo. Além disso, em uma situação de manobra, muitas vezes o motorista debruça-se sobre o volante em uma condição ante-ergonômica para conseguir realizar a manobra desejada. Desta forma, o condutor consegue melhorar a visibilidade traseira. A Figura 2 demonstra como os motoristas se posicionam para melhorar sua visibilidade e a visão que têm nesta condição. 

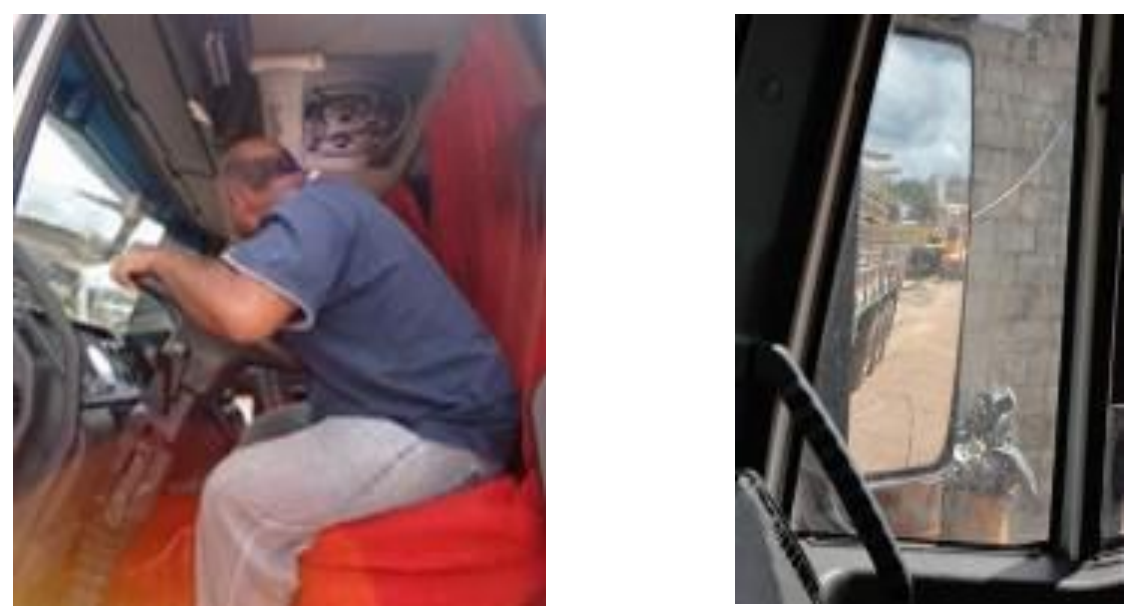

Figura 2: Motorista em condição ante-ergonômica e a visibilidade que possui nesta condição. (Fonte: Autor)

A segurança do condutor e dos demais usuários da via também é comprometida por esta perda de visibilidade. Não somente em manobras de pátio e de estacionamento que isto ocorre. Realizando curvas ou em manobras de esquina dentro de cidade, o motorista perde totalmente sua visão traseira, e assim, veículos de passeio e motos são facilmente não vistos por motoristas nestas situações.
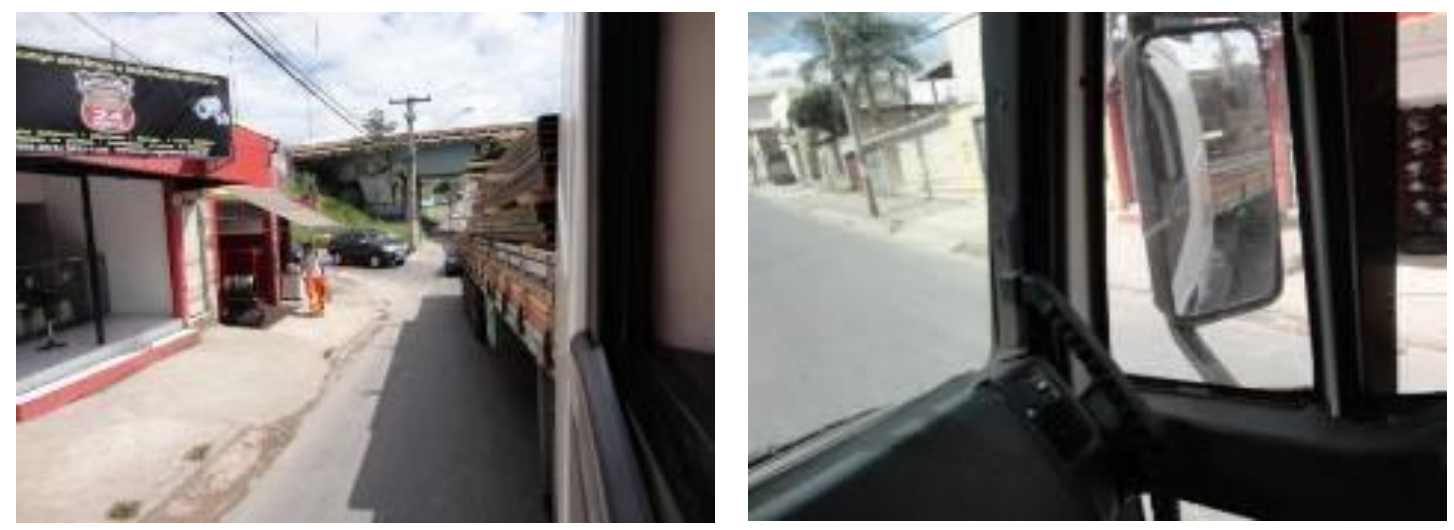

Figura 3: Veículo articulado realizando uma manobra de esquina dentro de cidade e a visão do espelho lateral direito nesta situação (Fonte: Autor)

1.2. Estudo em uma empresa de transporte urbano de passageiros com veículos articulados em sua frota

Foi realizado também, estudo de caso na Viação Euclásio Ltda., permissionária do transporte público de Belo Horizonte/MG, a qual foi recentemente incorporada ao sistema BRT da capital. Este modelo de transporte público, recentemente incorporado à cidade exige a utilização de veículos articulados de alta capacidade de passageiros. As permissionárias de Belo Horizonte, entre elas a Viação Euclásio, são empresas que em sua maioria nunca trabalharam com este tipo de veículo. Logo todos seus os motoristas autorizados a dirigir estes veículos são profissionais que em sua maioria, nunca haviam dirigido um veículo articulado e recentemente obtiveram a CNH de categoria $\mathrm{E}$. 
A empresa possui um amplo pátio e apenas dois veículos articulados. Segundo o gerente geral da empresa sr. Arnaldo Caldeira, até o momento não houve registro de acidentes, mas sim, foi reportada grande dificuldade de manobrar estes veículos por parte dos seus motoristas, principalmente em manobras à ré. A maior dificuldade registrada pela empresa é a pouca visibilidade traseira nos retrovisores. Os veículos da empresa são Neobus Mega BRT/Volvo os quais não possuem regulagem elétrica dos espelhos, o que segundo os motoristas dificulta as manobras, pois ao perder a visão lateral, não há como regular o espelho para melhorar esta condição.

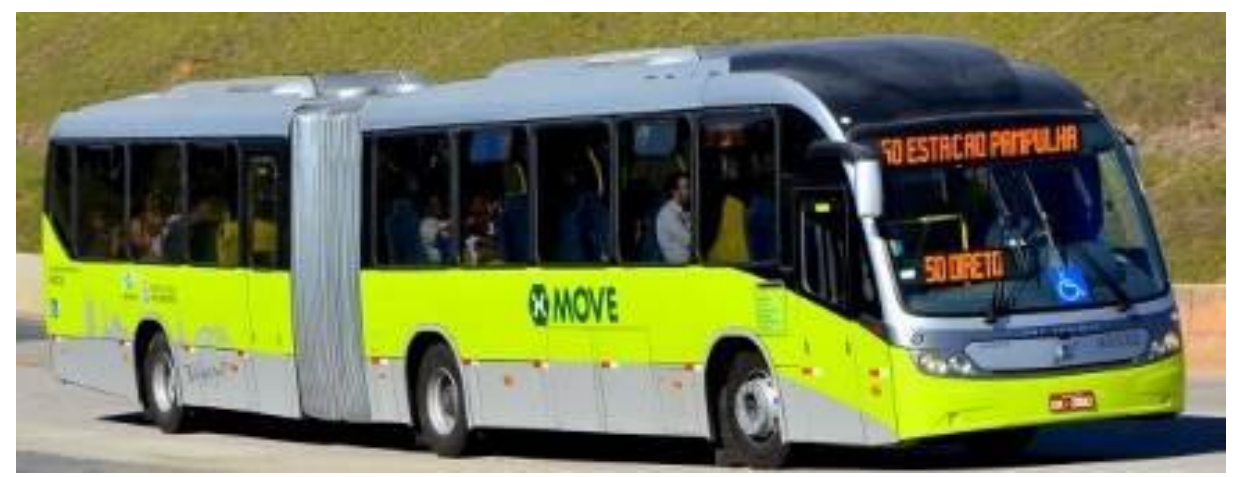

Figura 4: Ônibus Articulado da Viação Euclásio Ltda - Veículo Trator Longo/Veículo Rebocado Curto. (Fonte: onibusbrasil.com [1])

O ônibus articulado possui uma configuração diferenciada em relação aos veículos de carga articulados. Assim como é possível notar na Figura 4, a relação de comprimento entre veículo trator/veículo rebocado em que, o trator é curto em relação ao rebocado presente nos veículos de carga é inversa nos ônibus. Esta configuração veículo trator longo e veículo rebocado curto, afeta diretamente à dinâmica veicular e desta forma, no ônibus, com pequenos desalinhamentos entre as unidades veiculares, menores que no caminhão, constata-se também a perda de visão total no espelho retrovisor lateral como demonstrado na Figura 5 abaixo.
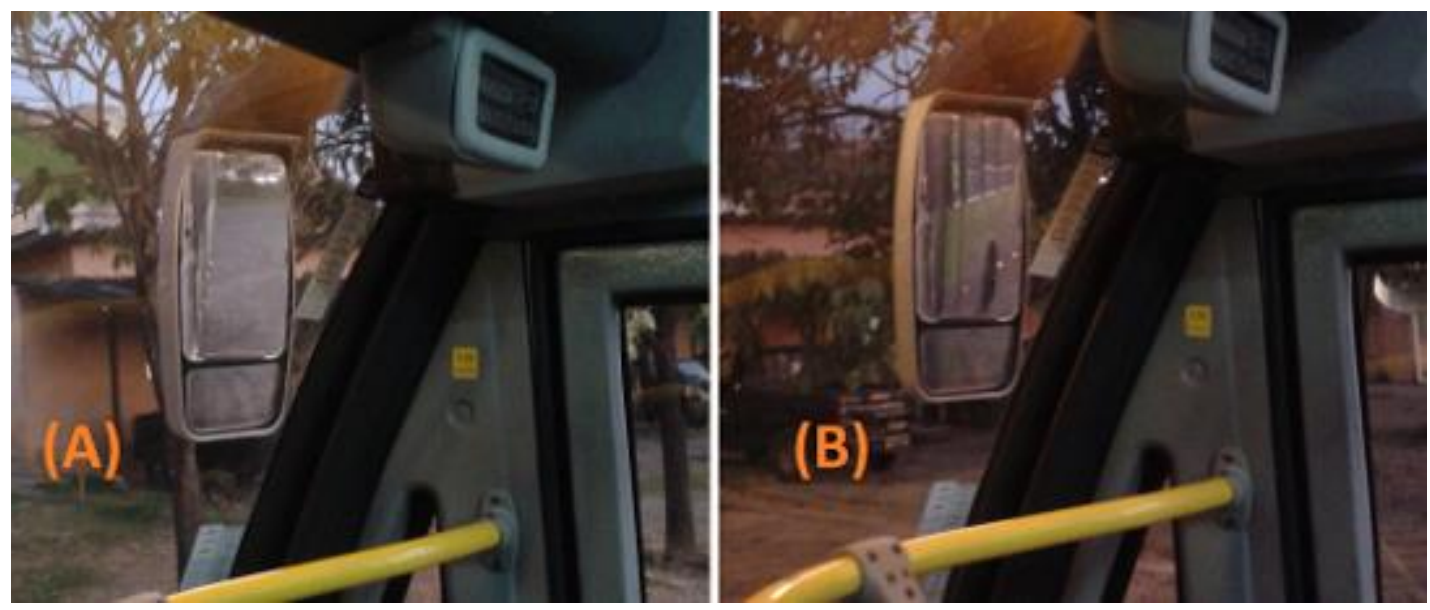

Figura 5: Visão do motorista no espelho retrovisor direito (A) Veículo Alinhado (B) Veículo no ponto de perca de visão total (Fonte: autor) 
Afim de calcular o ângulo entre os veículos da composição, manobrou-se o ônibus lentamente até que o motorista perdesse toda a visão no espelho lateral direito. De forma simultânea, foram realizadas marcações no assoalho na região da articulação do veículo conforme demonstrado na Figura 6. O ângulo em que o motorista perde totalmente a visão foi de apenas 5 graus.

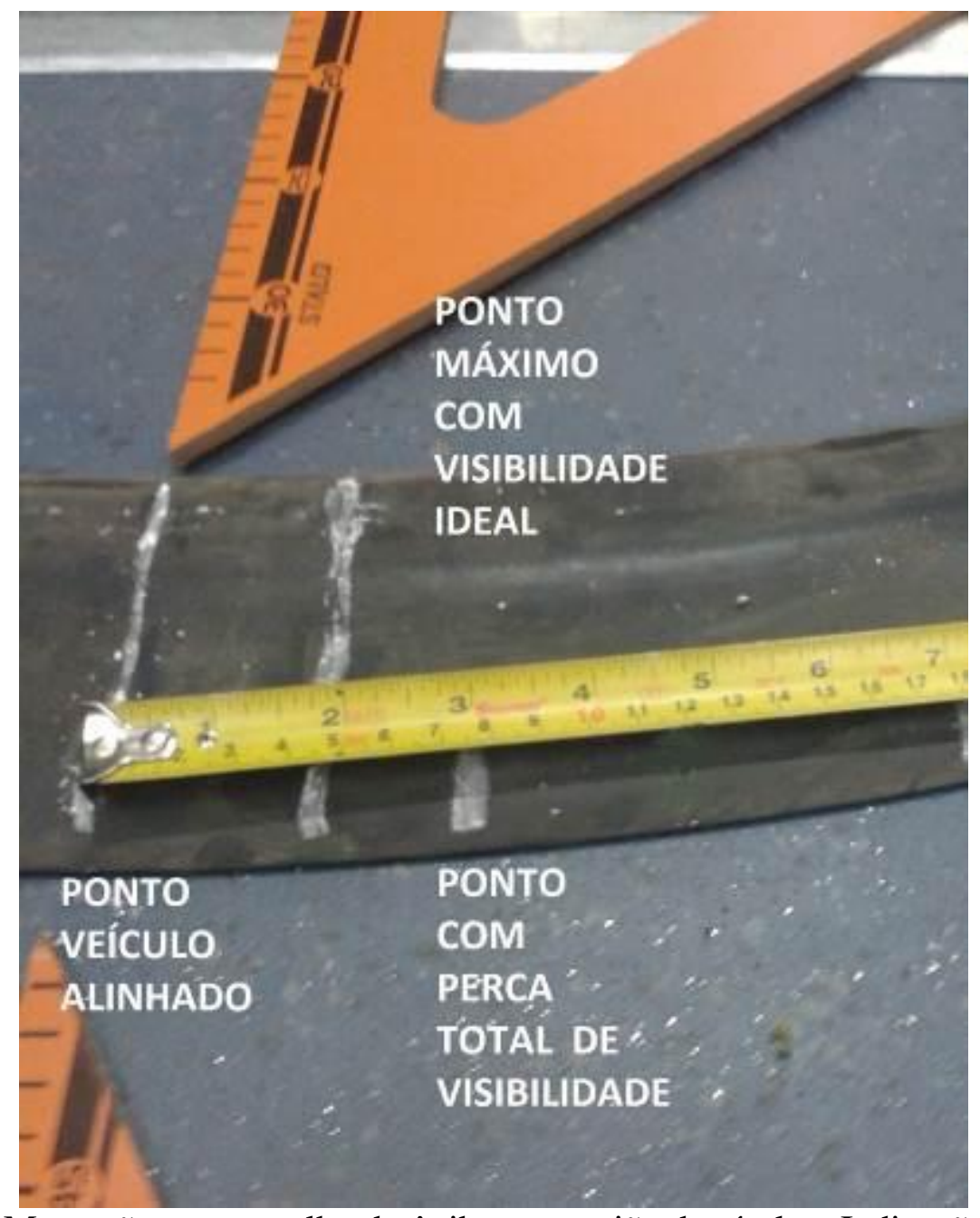

Figura 6: Marcações no assoalho do ônibus na região da rótula - Indicação do ponto em que há perda total da visibilidade no espelho retrovisor (Fonte: autor)

\subsection{Acidentes}

As figuras abaixo, demonstram alguns acidentes ocorridos devido à falta de visibilidade do motorista pelo espelho retrovisor lateral em situações de curva. Por se tratarem de pequenos acidentes, não é comum encontrar notícias a respeito, No entanto, segundo o próprio gerente da Empresa Transcouto, trata-se de acidentes comuns e corriqueiros nas empresas de transporte. Estes acidentes, mesmo que pequenos (sem vítimas letais), trazem grandes prejuízos às empresas, mesmo que com perdas materiais pequenas. Pois há uma queda considerável na produtividade do veículo, uma vez que o mesmo permanece em manutenção e compromete o cronograma de trabalho previsto para aquele veículo. Todos estes e muitos outros poderiam ter sido evitados caso o motorista tivesse visibilidade do final da composição veicular em curvas. 


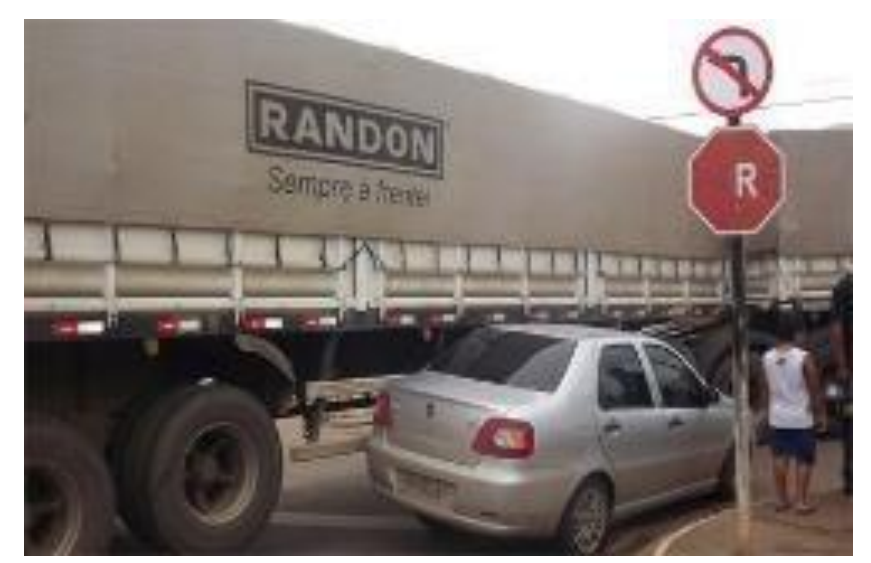

Figura 7: Acidente entre um bitrem e um carro de passeio (Fonte: Acervo do Autor)
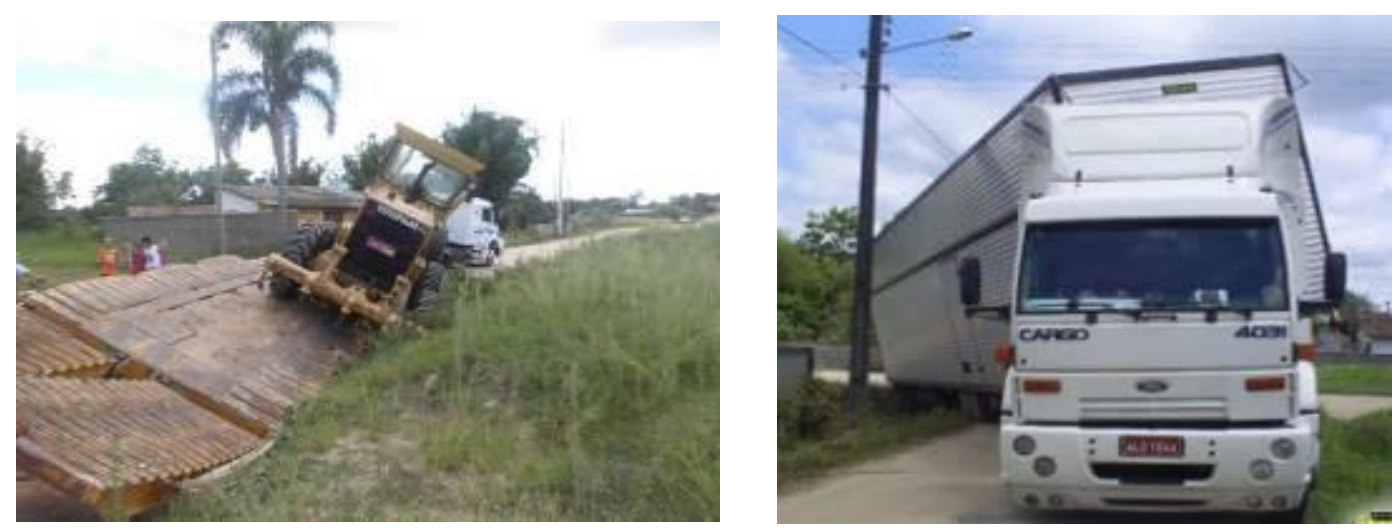

Figura 8: Acidentes em curvas fechadas, motorista não teve visão da trajetória do final da carreta (Fonte: Portal Canoinhas [2])

Nos Estados Unidos é comum a utilização de adesivos na traseira do veículo afim de alertar aos motoristas de veículos menores o risco de acidentes em curvas devido à falta de visão do motorista. No Brasil esta prática é adotada apenas por algumas empresas.
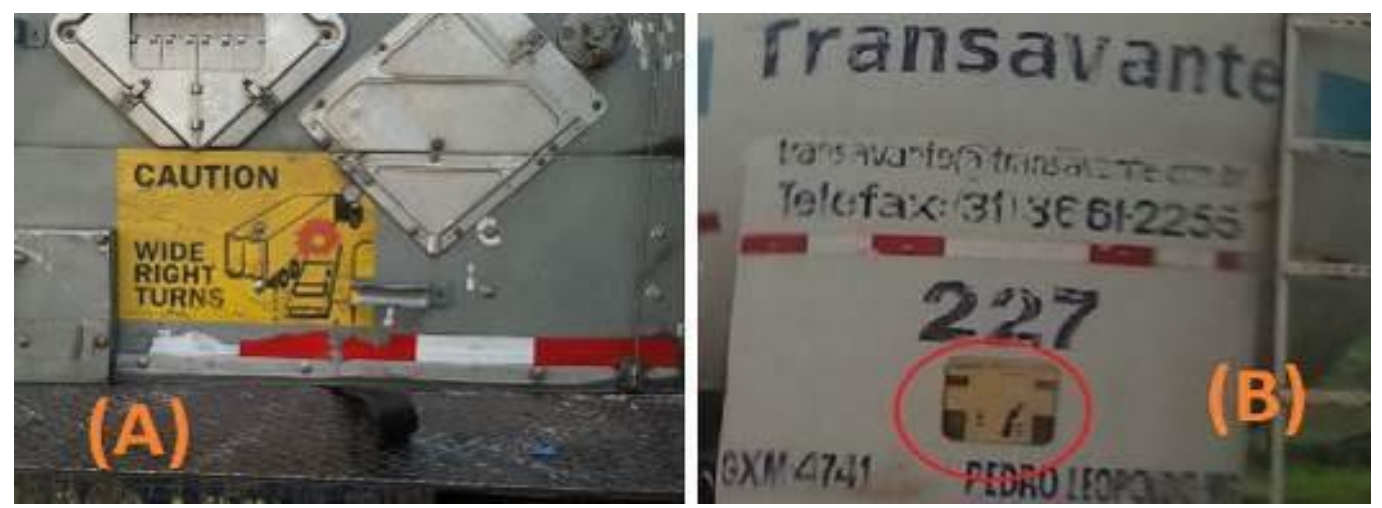

Figura 9: Adesivos de atenção na traseira do veículo - (A) Estados Unidos (B) Brasil (Fonte: Acervo do Autor) 


\section{CONCEITO DO SISTEMA}

\subsection{Apresentação}

O Sistema de Regulagem Automática para Espelhos Retrovisores de Veículos Articulados trabalha para que o motorista sempre mantenha sua visibilidade total em todas as situações. Seja realizando curvas, ou em situações de manobra. Na Figura 10 abaixo, pode-se compreender a variação do campo visual do motorista para os casos do veículo equipado com o Sistema de Regulagem Automática e sem o Sistema.
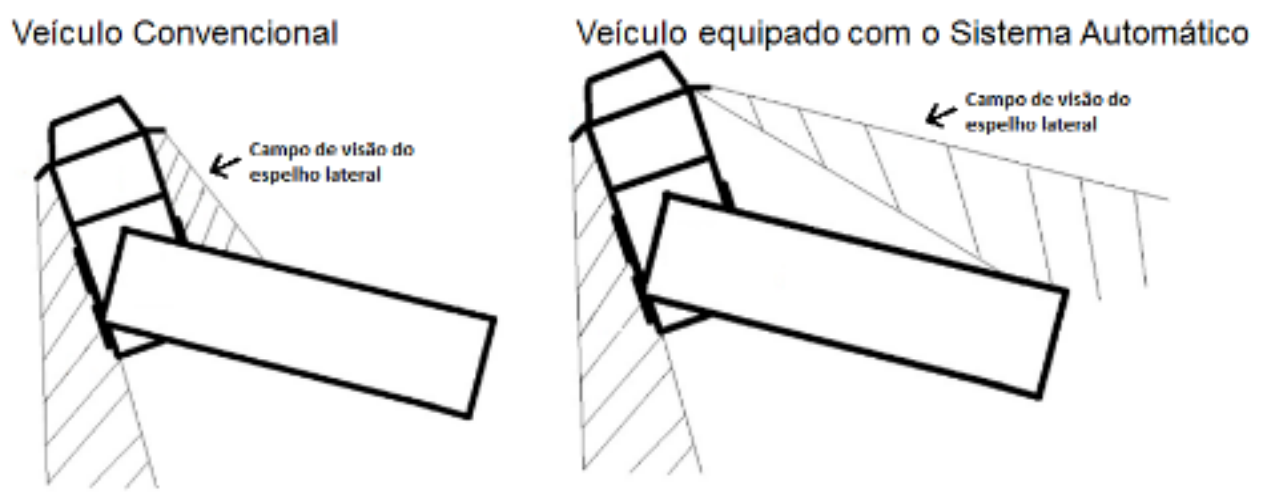

Figura 10: Campo de visão do espelho lateral com e sem o Sistema de Regulagem Automática (Fonte: Autor)

O Sistema de Regulagem Automática tem uma estrutura simples de funcionamento como apresentado na Figura 11. Este Sistema utiliza componentes de larga disponibilidade para indústria utilizando-se de tecnologia totalmente desenvolvida e conhecida:

- Espelho retrovisor lateral com regulagem elétrica (normal de produção);

- Uma central eletrônica de comando, a qual pode ser interligada à original do veículo e;

- Sensores para medição do ângulo na articulação do veículo.

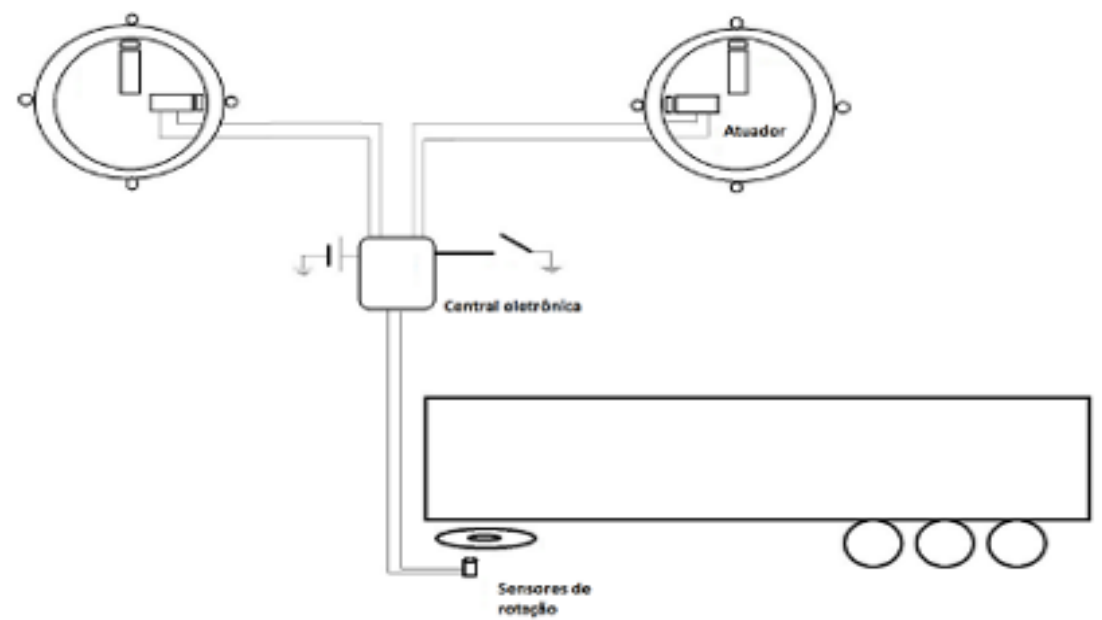

Figura 11: Esquema básico do Sistema de Regulagem Automática e seus principais componentes (Fonte: Autor) 
1.2. Descrição técnica do Sistema para caminhões articulados.

Para o perfeito funcionamento do sistema a referência básica é o ângulo formado entre as unidades veiculares. É através desse ângulo, que os espelhos são ajustados para manter o maior campo de visão possível ao motorista. No caso de caminhões articulados, a articulação é formada pelo contato de um pino (pino-rei) sobre uma peça com superfície lubrificada (quinta-roda). Ali, é instalado um sensor que fará a leitura deste ângulo e transmitirá à central eletrônica.

Para a aplicação em caminhões com articulação tipo pino-rei/quinta-roda, um fator de alta relevância para a abordagem técnica foi a agressividade do meio em que o sensor é submetido. Na concepção do projeto, foram descartados todos os sensores por contato e ópticos, que certamente não atenderiam a robustez necessária considerando-se as situações de vibração e a quantidade excessiva de graxa e sujeira na articulação da carreta. Como o pino-rei é uma peça normalizada, qualquer modificação (furos ou anteparos na peça) condenariam o projeto. A solução encontrada foi utilizar sensor magnético tipo Magnetômetro, o qual não tem interferência de funcionamento pela graxa e não necessita de contato físico [3]. Tendo em vista o ambiente da quinta-roda, este sensor foi a abordagem mais adequada. Desta forma, configurou-se uma solução robusta, resistente ao ambiente da articulação, com alta confiabilidade de dados e nenhuma modificação de projeto nas peças normais de produção.

O sensor magnético tipo Magnetômetro trabalha como uma bússola magnética o qual tem a função de indicar a direção do campo magnético da Terra. A solução técnica com menor modificação nas peças de produção, foi a inserção de um dispositivo magnético (imã,) fixado na superfície inferior do pino-rei [4]. Desta maneira, com a inserção do ímã próximo ao sensor, este passa a indicar a direção do campo magnético que está mais próximo e por consequência, a partir de algoritmos matemáticos, inferir o ângulo formado entre o veículo trator e a carreta.

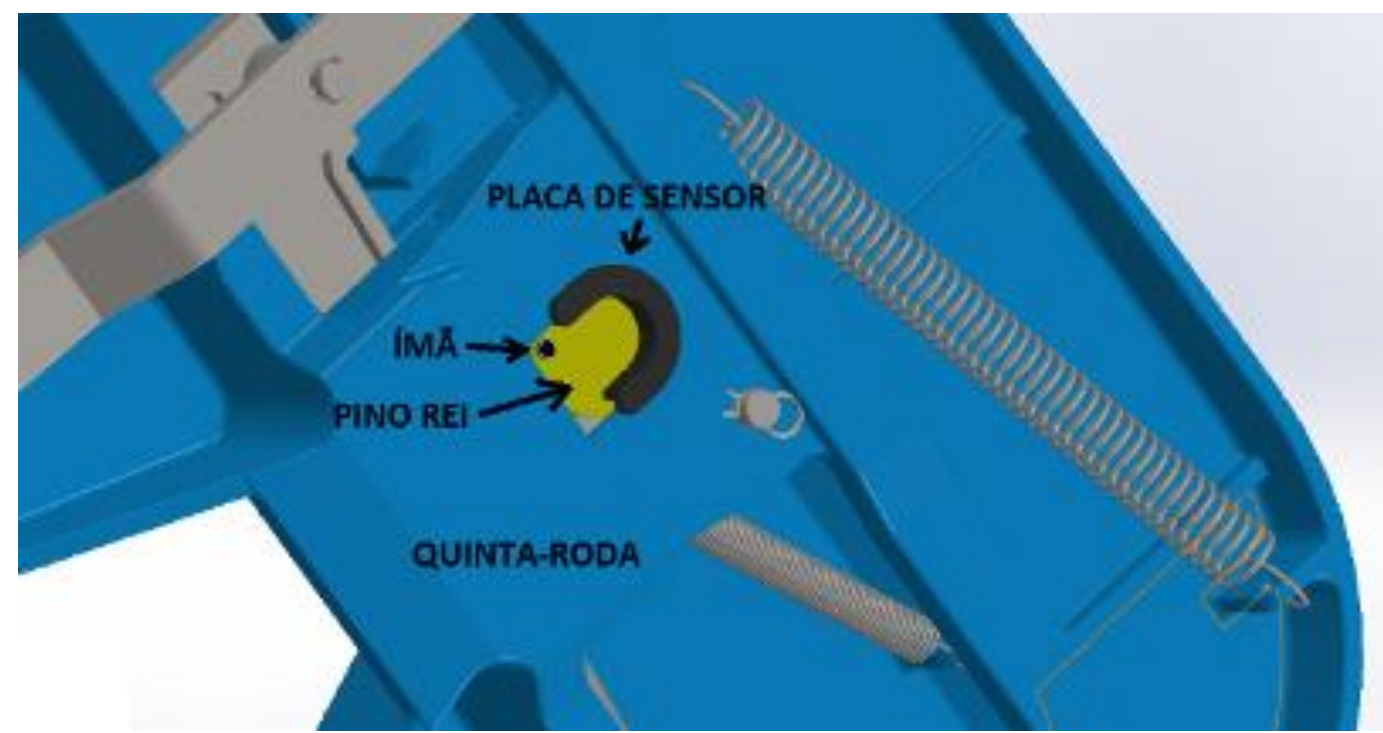

Figura 12: Vista inferior da quinta-roda com a placa de sensores e o pino-rei com o ímã em sua superfície inferior (Fonte: Autor) 
Dessa maneira, quando a carreta estiver engatada e girar em relação ao cavalo mecânico, a posição do ímã irá mudar em relação ao sensor e, a partir da variação do fluxo e direção do campo magnético será possível aferir o ângulo entre as unidades veiculares. A partir desta leitura, a central eletrônica processa a informação e atua no ajuste dos espelhos para manter o campo de visão mais adequado à posição das unidades veiculares.

O Sistema de Regulagem Automática necessita também atender veículos maiores, com maior número de veículos rebocados, onde o campo de visão é ainda mais prejudicado. Os bi-trens e rodo-trens (veículos com mais de um semi-reboque configuração muito comum no Brasil), necessitam de mais um parâmetro: que é a rotação do segundo veículo rebocado em relação ao primeiro veículo rebocado. Tal leitura faz-se necessária devido à diferença do campo de visão entre um veículo com apenas um veículo rebocado para um com dois veículos nesta mesma situação, como mostra a Figura 13 abaixo. Logo, para estes veículos faz-se necessária a leitura da rotação do pino-rei em relação à segunda quinta-roda.

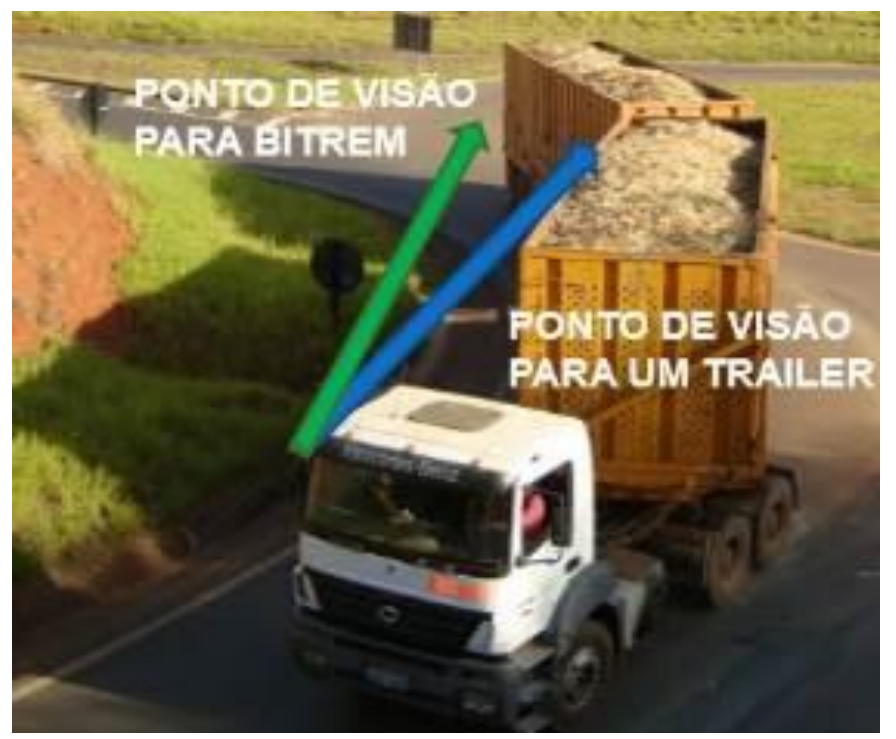

Figura 13: Campo de visão necessário para apenas um veículo rebocado e para um bitrem. (Fonte: Autor)

O veículo contará com dois sensores iguais (uma em cada quinta-roda) e nos dois pinos-reis haverão ímãs. Com estes dois parâmetros, a central eletrônica calculará a melhor rotação do espelho retrovisor para cada situação, da mesma forma que nos veículos com apenas uma articulação.

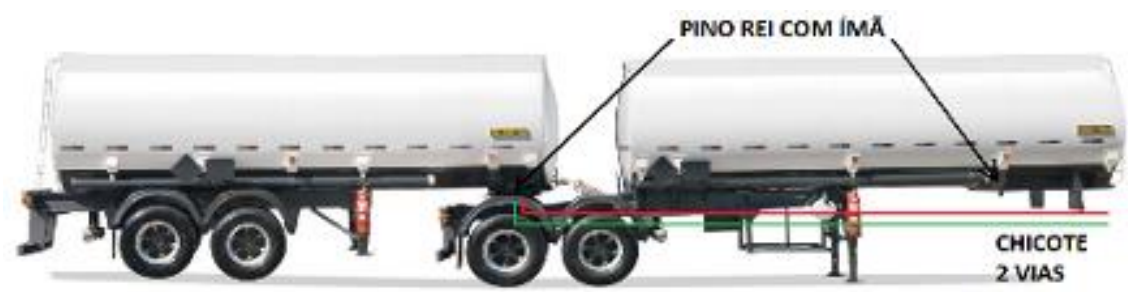

Figura 14: Chicote 2 vias necessário para aquisição do dado de rotação da segunda quinta-roda (Fonte: Modificado de Randon Implementos [5]) 
Os espelhos retrovisores com regulagem elétrica possuem dois atuadores, um vertical e outro horizontal, que podem ser acionados independentemente. Neste sistema apenas o atuador de rotação sobre o eixo vertical é acionado, mantendo a calibração sobre o eixo horizontal feita pelo motorista. Quando o veículo retornar a posição original (ângulo de 180 graus entre cavalo e carreta), o espelho também voltará a posição original calibrada pelo motorista.

\subsection{Descrição técnica do Sistema para ônibus articulados.}

A instalação em ônibus articulado utiliza-se da mesma solução técnica e sensor tipo Magnetômetro igual aos caminhões com articulação tipo pino-rei/quinta-roda. A diferença encontra-se na disposição dos componentes, visto que a articulação do ônibus não possui pino-rei, quinta-roda e desacoplamentos constantes.

A solução para ônibus articulados proposta para este sistema foi elaborada tendo em vista a composição do ônibus articulado que é de basicamente duas peças de dois fabricantes distintos: o chassi e a carroceria, que podem ser montados através de diversas combinações [6]. Tal disposição do Sistema de Regulagem Automática proposta para ônibus articulados utiliza-se apenas de componentes da carroceria que possui toda a interface com os espelhos retrovisores. Desta forma o magnetômetro é posicionado sob o assoalho do segundo carro, e o ímã sob o assoalho da rótula. Como estas peças possuem movimento relativo de translação, é possível através desta configuração aferir o ângulo entre os veículos. Conforme Figura 15 abaixo e analogamente à solução dos caminhões, para ônibus com mais de uma articulação, é necessário a aquisição de dados em todas elas.

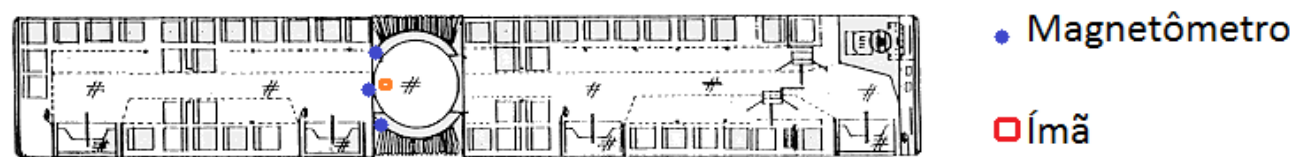

\section{ÔNIBUS ARTICULADO}

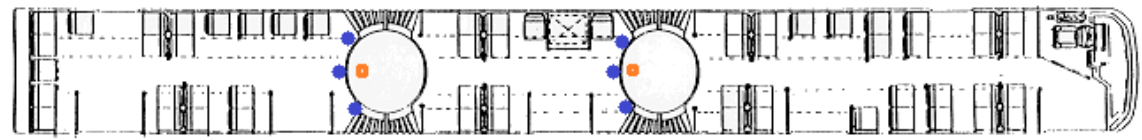

\section{ÔNIBUS BIARTICULADO}

Figura 15: Disposição da solução técnica para ônibus articulados e biarticulados (Fonte: Acervo do Autor) 


\section{PROTÓTIPOS}

1.1. Protótipo A - Aprovação do conceito

Para provar o conceito do Sistema de Regulagem Automática para Espelhos Retrovisores de Veículos Articulados foi realizado um teste de bancada utilizando a solução Arduino. Este teste possuiu as seguintes características:

- Central Eletrônica por Arduino

- Ligações de sensor realizadas em Pin-board

- Utilização de uma bancada similar a configuração no caminhão.

- Utilização de um retrovisor comercial Scania com comando elétrico.
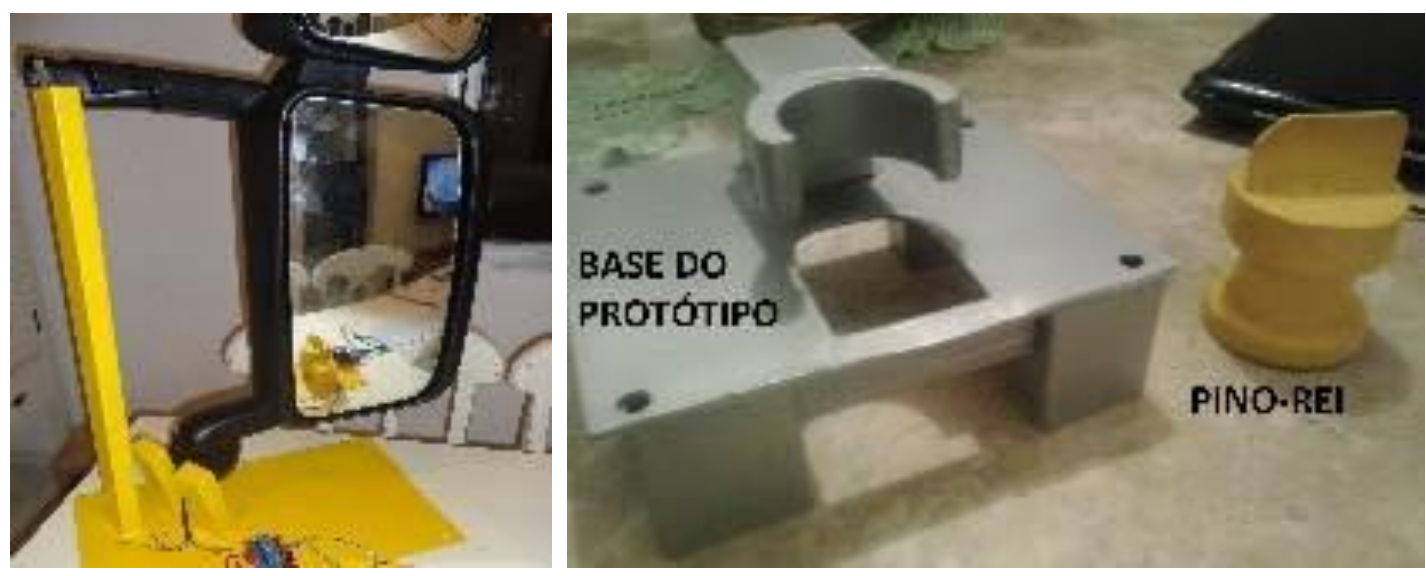

Figura 16: Base para o espelho retrovisor (esquerda) e base para o pino-rei (direita).

(Fonte: Autor)
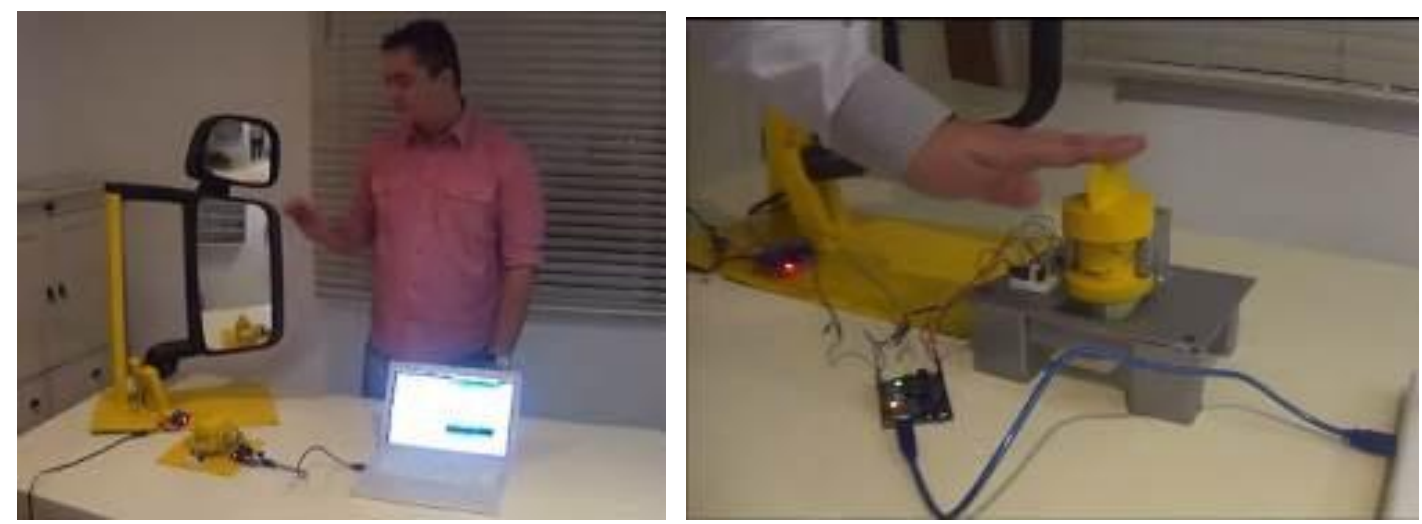

Figura 17: Apresentação do Protótipo A do Sistema Automático

(Fonte: youtube.com[7])

O protótipo obteve sucesso ao apresentar o conceito, provando tecnicamente que seria possível o avanço dos testes com as soluções técnicas selecionadas. O resultado pode ser visto em: http://youtu.be/G4PfFxKT7U8 [7]. 
1.2. Protótipo B - Validação em condição estática e montado em uma quinta-roda

Para provar a robustez quando instalado tal como em um veículo real, o Sistema de Regulagem Automática para Espelhos Retrovisores de Veículos Articulados foi submetido à testes, havendo sido instalado em um quinta-roda, contando com os seguintes aspectos:

- Central Eletrônica dedicada.

- Cabos e conexões fabricados para atender a solução.

- Instalação em uma quinta-roda.

- Utilização do espelho retrovisor comercial Scania com comando elétrico.

- Teste estático simulando condição real.

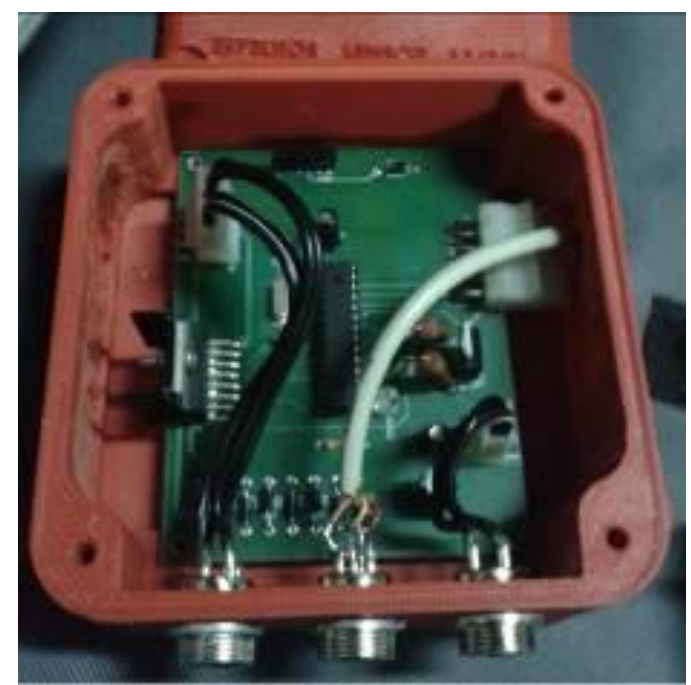

Figura 18: Central Eletrônica dedicada ao Sistema de Regulagem Automática (Fonte: Autor)

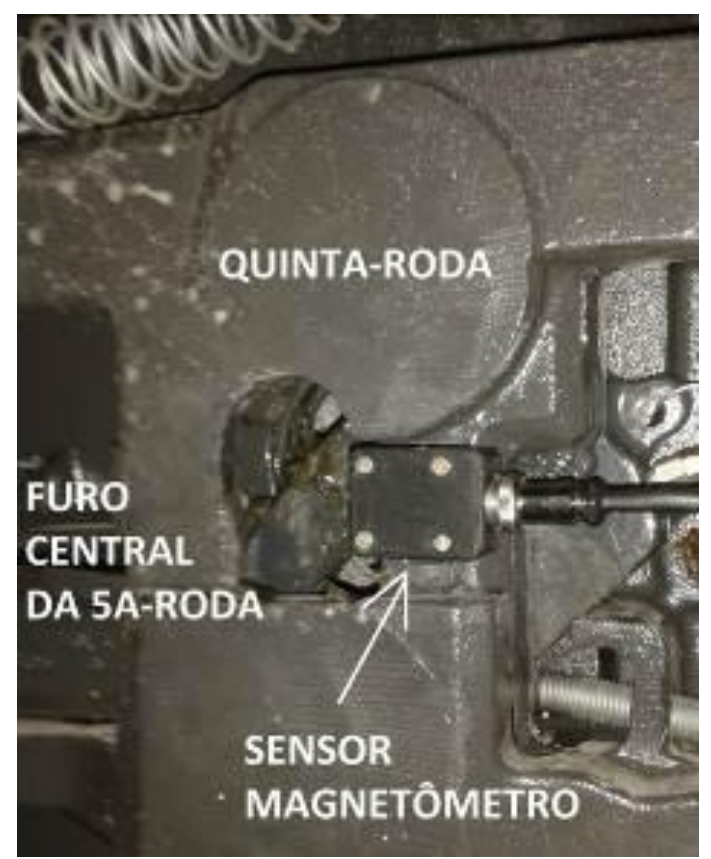

Figura 19: Vista inferior da quinta-roda demonstrando a posição de fixação do sensor Magnetômetro (Fonte: Autor) 


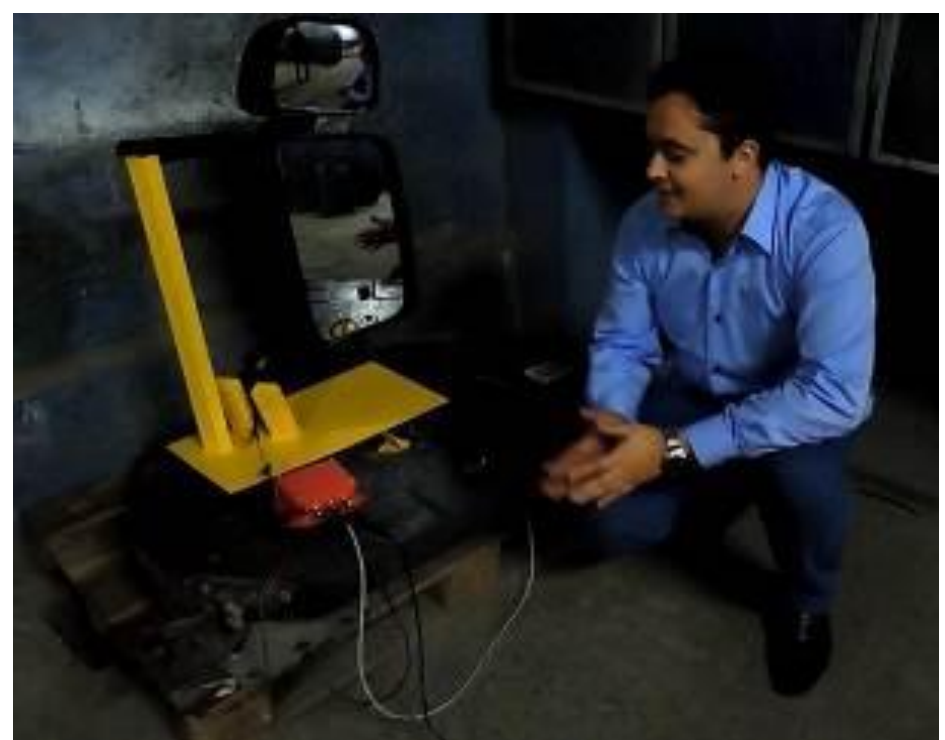

Figura 20: Apresentação do Sistema instalado em uma quinta-roda

(Fonte: youtube.com [8])

O protótipo B obteve sucesso ao ser colocado à prova, instalado em uma quinta-roda devidamente engraxada, assim como em um veículo real. Ao ser testado, o protótipo provou ser capaz de rodar em um veículo sujeito às condições reais do ambiente. $\mathrm{O}$ resultado pode ser visto em: https://youtu.be/ujrJ6fDxTzk [8].

\subsection{Protótipo C - Validação do Sistema em um veículo}

Como teste final, o Sistema de Regulagem Automática para Espelhos Retrovisores de Veículos Articulados foi submetido à instalação completa em uma carreta. Este teste contou com os seguintes aspectos:

- Central Eletrônica dedicada.

- Cabos e conexões fabricados para atender a solução.

- Montado em um cavalo mecânico VW Constellation 19.320 e uma carreta Randon Carga Seca devidamente engraxada.

- Sujeito às condições reais de uso.
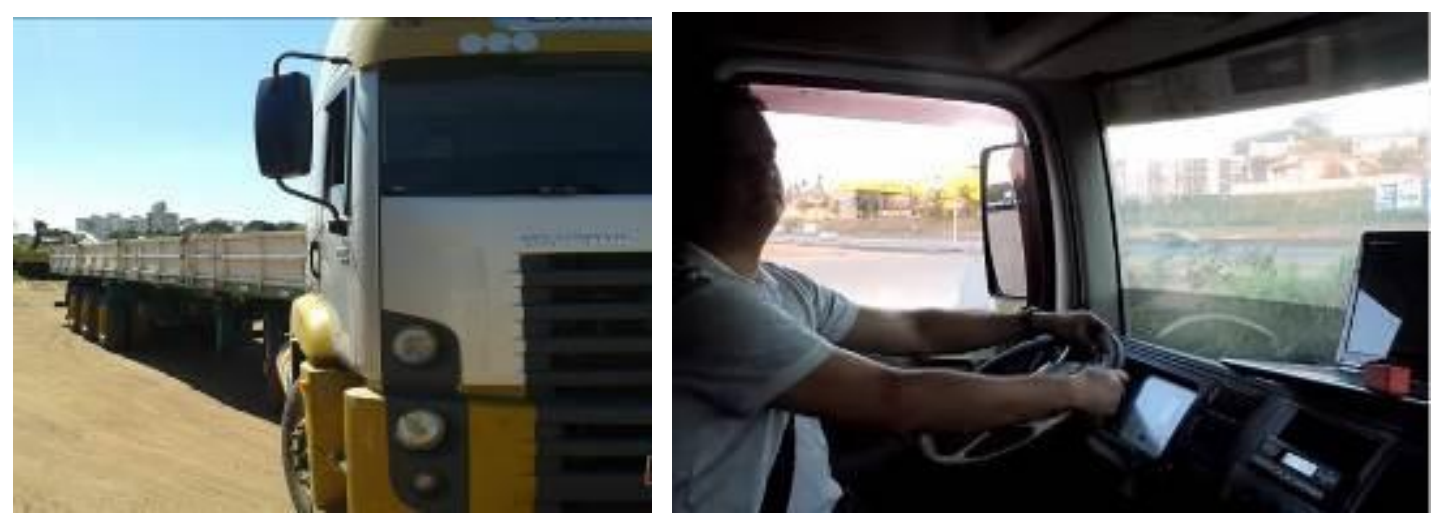

Figura 21: Sistema sendo testado em um VW Constellation - Posição de calibração de acordo com a visão do motorista no espelho retrovisor (Fonte: youtube.com [9]) 
Para a validação do sistema nesta condição foi necessária calibração de acordo o conjunto veicular utilizado no teste. Desta forma, foi observada a visibilidade do motorista no retrovisor do lado direito e a partir da leitura do sensor instalado na quinta-roda sob monitoramento do computador, foi verificado o ponto exato no qual o espelho deveria se mover para permitir ao motorista, uma visão do final da composição. A Figura 21 apresenta este procedimento e demonstra a posição do veículo onde o motorista perde toda visibilidade traseira. É apresentada na Figura 22 abaixo a visão do motorista com o Sistema de Regulagem Automática desligado e ligado.
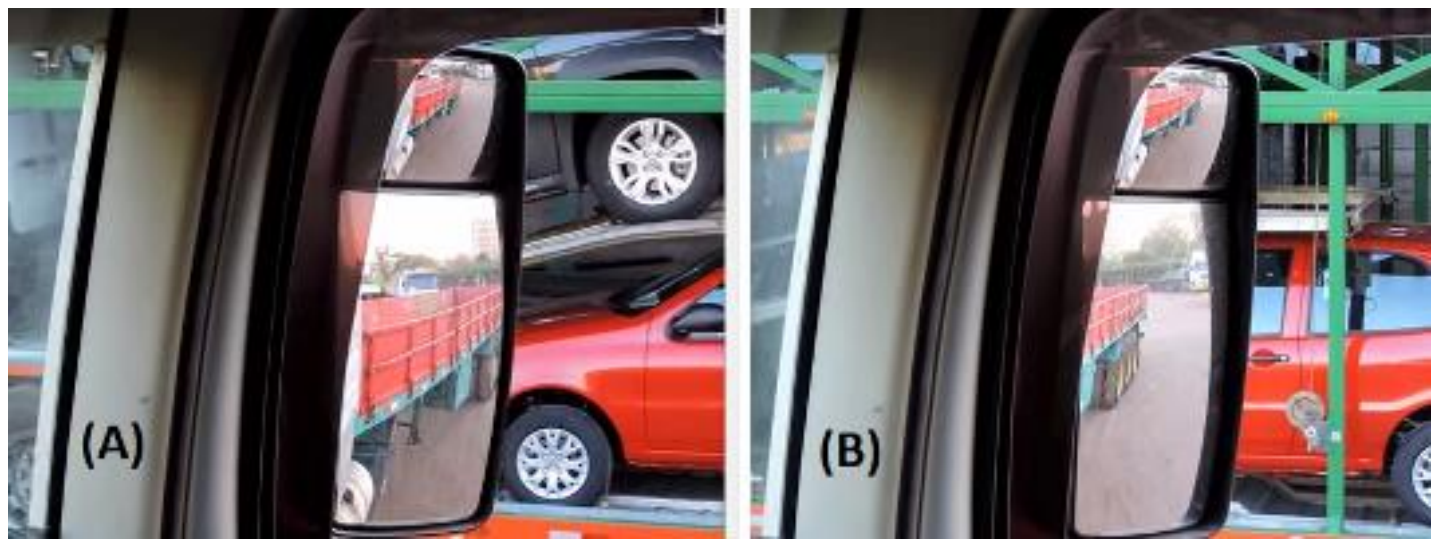

Figura 22: Visão do motorista no espelho retrovisor do lado direito:

(A) Sistema de Regulagem Automática desligado

(B) Sistema de Regulagem Automática ligado (Fonte: youtube.com [9])

O protótipo C final obteve o resultado esperado quando instalado no veículo. Com o Protótipo C (final) do Sistema de Regulagem Automática foi possível validar fisicamente os ganhos em conforto e segurança para o motorista. Sujeito ao ambiente de vibração, graxa e sujeira da quinta-roda, o sensor obteve leituras precisas e estáveis, tendo sido aprovado para esta aplicação. O resultado pode ser visto em: https://youtu.be/Zo5e1Ny2efE [9].

\section{VIABILIZAÇÃO DO SISTEMA AUTOMÁTICO}

O projeto do Sistema de Regulagem Automática tem como seu principal alicerce de viabilidade o aumento considerável de segurança para o motorista e demais usuários do transporte rodoviário. O motorista poderá contar com um sistema automatizado que facilitará seu trabalho, aumentará sua produtividade com conforto e ergonomia. Para viabilizar o projeto do Sistema de Regulagem Automática para Espelhos Retrovisores de Veículos Articulados, o mesmo foi concebido de forma interferir minimamente no projeto original do veículo.

Para veículos em uso, necessita-se apenas que o espelho retrovisor possua regulagem elétrica. As modificações de projeto limitam-se apenas a adequações de chicote, inserção da central eletrônica do Sistema no veículo e instalação do sensor na quinta-roda. Visto não haver grandes modificações de projeto e necessitar-se apenas que o veículo possua espelhos retrovisores com regulagem elétrica, facilita a aplicação do projeto em veículos em uso e reduz o custo inicial de implementação para veículos novos. Desta forma, o Sistema de Regulagem Automática mostra-se de grande viabilidade para todas as aplicações. 
1.1.Viabilidade financeira

O sucesso do projeto vem com sua simplicidade de concepção, para um mercado extremamente competitivo, com produtos de alto valor agregado e clientes exigentes por tecnologia, onde um pequeno diferencial de melhor qualidade e valor de produto podem ser decisivos para concluir a compra. Mesmo com grande valor agregado o sistema possui um baixo custo, tanto para seu desenvolvimento quanto ao custo peça. $\mathrm{Na}$ Tabela 1 segue uma estimativa de investimentos e custo peça do sistema.

\begin{tabular}{|c|cc|}
\hline COMPONENTE & INVESTIMIENTO & CUSTO PEÇA \\
\hline Central Eletrônica (Programação e teste) & $\mathrm{R} \$ 1.000 .000,00$ & $+\mathrm{R} \$ 10,00$ \\
\hline Botão ON/OFF para o Sistema & $\mathrm{R} \$ 200.000,00$ & $+\mathrm{R} \$ 8,00$ \\
\hline Chicotes elétricos (Novo layout) & $\mathrm{R} \$ 50.000,00$ & $+\mathrm{R} \$ 2,00$ \\
\hline Sensor de rotação (Programação e teste) & $\mathrm{R} \$ 500.000,00$ & $+40,00$ \\
\hline TOTAL & $\mathbf{R} \$ \mathbf{1 . 7 5 0 . 0 0 0 , 0 0}$ & $\mathbf{R} \$ \mathbf{6 0 , 0 0}$ \\
\hline
\end{tabular}

Tabela 1: Estimativas de investimento e custo peça para o Sistema

O preço estimado de venda do Sistema é de aproximadamente $\mathrm{R} \$ 1.000,00 \mathrm{em}$ um veículo novo. O valor de um caminhão Scania G440 6x2 Highline novo, completo, chega a custar hoje em médica $\mathrm{R} \$ 370.000,00$. Neste caso, o Sistema de Regulagem Automática custará apenas cerca $0,3 \%$ do preço do veículo, mostrando toda sua viabilidade econômica de venda e uma grande possibilidade de lucro para a montadora, tendo em vista o baixo custo peça.

\subsection{Viabilidade Comercial}

O sucesso para a viabilidade comercial do projeto se faz com sua aceitação pelo mercado. Segue abaixo opiniões de profissionais do setor de transportes:

"É difícil hoje encontrar um bom motorista, (...) pequenos acidentes porque o motorista perdeu a carreta no espelho e esbarrou em outro caminhão, ou em um carro ou no poste são comuns em toda empresa de transportes, acabamos perdendo muito com isso. Espero ver este projeto em breve à venda."

- Ricardo Camargos, Gerente de Frota da Trans Couto Ltda..

"Com relação a invenção, achei muito boa, funcional e em prol da segurança da sociedade. É inquestionável. (...) Gostaria muito de ver esse sistema nos novos caminhões."

- Juliano Pimentel Gerente de Inovação da Randon Implementos.

"Hoje em Belo Horizonte, trabalhamos em vários pontos da cidade com trânsito misto. $O$ compartilhamento da mesma via por ônibus articulado e veículos menores gera sérios riscos de colisões entre eles. Nos veículos articulados existem vários pontos cegos, esta inovação, o Sistema de Regulagem Automática, certamente reduzia índices de acidentes com ônibus articulados em grandes centros urbanos e também nas manobras dentro da garagem."

- Arnaldo Caldeira, Gerente Geral da Viação Euclásio Ltda. 
"Achei uma excelente ideia, (...) certamente facilitaria meu trabalho. Manobrar o ônibus articulado na garagem e nas estações é praticamente impossível sem auxílio de um colega."

- Geraldo Nadir, Motorista à 20 anos da Viação Euclásio Ltda.

\section{CONCLUSÃO}

O Sistema de Regulagem Automática para Espelhos Retrovisores de Veículos Articulados surgiu da análise crítica a uma situação do dia-a-dia vivida por várias pessoas. Com essa análise e os conhecimentos sobre o mercado surgiu uma solução simples e inovadora de alta performance na resolução do seu problema chave.

Com o Sistema de Regulagem Automática para Espelhos Retrovisores de Veículos Articulados instalado em um veículo, foi notável o ganho de segurança, conforto e facilidade de manobra para o motorista. Com este Sistema, o risco de acidentes por falta de visibilidade traseira será reduzido e aumentará o conforto e ergonomia do motorista. Poder-se-á verificar também um aumento de produtividade do veículo devido a redução do tempo de manobra e à redução de paradas por pequenos acidentes. Toda esta melhoria resume-se a um sistema de baixo custo, mínima modificação de projeto e baixo investimento inicial, por utilizar componentes de larga utilização na indústria.

Em suma, uma solução inteligente, de alto valor agregado, com baixo investimento de desenvolvimento e um baixo custo de peça unitário. Uma descrição de caso de sucesso de uma simples ideia que se torna real para o benefício de milhares de pessoas.

\section{REFERÊNCIAS}

[1] ONIBUS BRASIL. Ônibus Viação Euclásio Ltda. - Disponível em: http://onibusbrasil.com/foto/2754067. Acesso em: 20 de maio de 2015.

[2] PORTAL CANOINHAS. Caminhão cai em Valeta - Disponível em: http://www.portaldecanoinhas.com.br/clickportal/0836. Acesso em: 20 de maio de 2015.

[3] BATISTA, Igor; FERREIRA, Gabriel. Retrovisor Automático para Caminhões e Ônibus Articulados, Instituto Nacional da Propriedade Intectual - INPI, Belo Horizonte/MG Registro no. BR 102014022587 0, Data 12 de setembro de 2014.

[4] BATISTA, Igor; FERREIRA, Gabriel. Disposição de Pino Rei Magnético, Instituto Nacional da Propriedade Intectual - INPI, Belo Horizonte/MG Registro no. BR 202015 004320 7, 27 de fevereiro de 2015.

[5] RANDON IMPLEMENTOS. Bitrem Tanque - Disponível em: http://www.randonimplementos.com.br/uploads/Bitrem-Tanque-Safety-Multisetas_2_03.jpg. Acesso em: 20 de maio de 2015.

[6] BATISTA, Igor; FERREIRA, Gabriel. Método de Medição Angular para Ônibus Articulados, Instituto Nacional da Propriedade Intectual - INPI, Belo Horizonte/MG Registro no. BR 102013029281 8, 13 de novembro de 2013. 
[7] YOUTUBE. Retrovisor com Regulagem Automática para Caminhões e Ônibus Disponível em: http://youtu.be/G4PfFxKT7U8. Acesso em: 20 de maio de 2015.

[8] YOUTUBE. Retrovisor Automático para Caminhões e Ônibus - Protótipo B - Disponível em: https://youtu.be/ujrJ6fDxTzk. Acesso em: 20 de maio de 2015.

[9] YOUTUBE. Protótipo C - Espelho Automático- Disponível em: https://youtu.be/Zo5e1Ny2efE. Acesso em: 20 de maio de 2015.

\section{AGRADECIMENTOS}

Os autores do projeto agradecem a Viação Euclásio Ltda e a Trans Couto Ltda pela participação e colaboração com o projeto, fundamentais para os resultados deste trabalho. 